\title{
25 Research Soure \\ Risky Sexual Behaviour among Male Immigration and Correctional Personnel in Kano State, Nigeria, 2018
}

Nureni Azeez ( $\nabla$ dhu_nurain2006@yahoo.com )

Ahmadu Bello University/Nigeria Field Epidemiology and Laboratory Training Program https://orcid.org/0000-0002-8567-1481

Aishat Bukola Usman

African Field Epidemiology Network

Adebowale Ayo Stephen

Department of Epidemiology and Medical Statistics, University of Ibadan

Abubakar Muhammad Jibo

Department of Community Medicine, Bayero University, Kano

\section{Zubairu lliyasu}

Department of Community Medicine, Bayero University, Kano

Research article

Keywords: Sexual risk behaviour, Uniformed men, Sexually transmitted infections, Kano state

Posted Date: April 29th, 2020

DOl: https://doi.org/10.21203/rs.3.rs-21901/v1

License: (c) (1) This work is licensed under a Creative Commons Attribution 4.0 International License. Read Full License 


\section{Abstract \\ Background}

Worldwide, uniformed personnel have been recognized as a population at high risk for sexually transmitted infections because of their high mobility, power differentials and affluence. However, limited research studies have been documented on risky sexual behaviour (RSB) among male uniformed personnel in Nigeria. We conducted this study to determine the prevalence and identify the predictors of RSB among male immigration and correctional personnel in Kano State.

\section{Methods}

We conducted a cross-sectional study among 306 male immigration and correctional personnel using multi-stage sampling technique. A pre-tested self-administered structured questionnaire containing sociodemographic and variables associated with RSB was used for data collection. Indicators of RSB included transactional sexual intercourse, sexual intercourse with casual acquaintances and multiple non-regular sexual partner over the last 12 months. Data were analysed using descriptive statistics, Chisquare test and logistic regression $(a=0.05)$.

\section{Results}

Mean age of the respondents in the immigration and correctional services were $37.9 \pm 9.3$ and $38.0 \pm$ 8.1 years respectively. Overall prevalence of RSB was $15.1 \%$ (9.2\% and $20.9 \%$ among correctional and immigration workers respectively). The identified predictors of RSB were service group, marital status and attending club house prior to sexual intercourse. The likelihood of RSB was lower among the correctional personnel $(\mathrm{aOR}=0.38, \mathrm{Cl}=0.17-0.80)$ than the immigration officers. Being married is protective of RSB $(\mathrm{aOR}=0.38, \mathrm{Cl}=0.18-0.81)$ while attending club house prior to sexual intercourse predisposes the uniform personnel to $\mathrm{RSB}(\mathrm{aOR}=3.90, \mathrm{Cl}=1.30-11.68)$.

\section{Conclusions}

Risky sexual behaviour was highly prevalent among the investigated uniform men but was higher among immigration officers than the correctional personel. Effective health education on the possible implication of RSB is highly recommended for immigration and correctional personnel.

\section{Background}

Sexual behaviour is a complex private activity which is subject to social, cultural, moral and legal considerations [1]. Although there is no specific definition for risky sexual behaviour (RSB), it is usually referred to any behaviour that predisposes individuals to the risk of contracting sexually transmitted 
infections including HIV/AIDS and unplanned pregnancy [2]. The RSB is often classified into two broad categories; indiscriminate sexual behaviours like keeping multiple partners, having risky, casual or unknown partners and also failure to take protective actions, such as use of condoms and birth control [3].

Uniformed personnel are often described as being a high-risk population for RSB as they are primarily male, young, sexually active, and often lack access to comprehensive sexual and reproductive health information and services [4]. They belong to mobile populations group and usually spend long period of time away from home, their families, spouses, or partners, which may increase their susceptibility to engaging in casual sex with non-stable partners or sex workers [5]. Their access to ready cash in their place of deployment makes them a focus of patronage by both casual and commercial sex workers [6].

Willingness to accept and engage in risk-taking is central to many uniformed services and is strongly associated with readiness for combat [7]. This core attribute of many uniformed services might predispose personnel to engage in other high-risk behaviours, such as unprotected sex. The impact of RSB on the uniformed services in the African countries is alarming [8]. It is estimated that sexually transmitted infection rates among uniformed personnel are generally 2 to 5 times higher than in civilian populations $[8,9]$ and prevalence rates of HIV between $5.8 \%$ and $26.7 \%$ have been reported from different studies among uniformed services personnel in countries in Africa [10]. With this high prevalence of infection and risky sexual behaviour among uniformed men, sustenance of high HIV and STIs prevalence in Africa is imminent if unchecked.

Despite the fact that uniformed personnel have been recognized as a population at high risk for sexually transmitted infections (STIS) and HIV infection [11, 12], limited research exists on STIs and risky sexual behaviour among uniformed personnel most especially in Nigeria immigration and correctional services. Periodic national survey carried by the Federal Ministry of Health in Nigeria under Integrated Behavioural and Biomedical Surveillance Survey (IBBSS) has consistently involved members of armed forces and the police as study participants [13]. Conditions of service of Nigeria immigration and correctional workers are similar to those of military and police, although their risk patterns could be different because of the nature of their postings and duties. To fill this gap, this study determined the prevalence and identified predictors of risky sexual behaviour among male immigration and correctionals personnel in Kano State.

\section{Methods}

\section{Study Area}

This study was conducted in Kano State which is located in the North-western geopolitical zone of Nigeria. Administratively, Kano State has 44 Local Government Areas. The State is densely populated with over 15 million people according to the estimates projected from the 2006 Nigeria population census exercise. 
The Nigeria immigration service in Kano State has a total of seven (7) different units. The units include the command headquarters, Mallam Aminu Kano international airport, farm center passport office, Immigration training school, Amana city passport office, anti-human trafficking and resident permit office. The Kano State command of Nigeria Correctional Service comprises of the command headquarters, Goron Dutse correctional center, Kano central correctional center, Wudil correctional center and small satellite correctionals center located in Rano, Bichi, Gwarzo, Sumaila and Dawaki Tofa LGAs. Both immigration and correctional services have small health facility each and limited accommodation was provided for their personnel. The personnel are posted from different parts of Nigeria and in most situation, they may not move with their families with the view that they could be reposted to another location at any time. All immigration and corrected personnel are adults (aged 18 years and above) and predominantly belong to sexually active population.

\section{Study Population}

Study population consisted of personnel of Nigeria immigration and correctional services in Kano State. Immigration and correctional personnel $(\mathrm{n}=306)$ with minimum of 12 months at duty post in Kano State were included in the study.

\section{Study Design}

It was a cross-sectional descriptive study.

\section{Sampling Technique}

A 2-stage sampling technique was used to select the eligible participants for this study. At the first stage, 3 units each were randomly selected from the 7 units and 9 units in the immigration offices and correctional centers in Kano state respectively. The 3 units selected among the immigration offices are farm center passport office, immigration training school and the command headquarters while command headquarters, Goron Dutse correctional and Kano central correctional centers were the 3 units selected among the correctional centers. The list of the personnel in the selected units was compiled based on their cadre (rank). Thereafter, a proportionate allocation of sample to each cadre in each selected unit was done. Thereafter, the participants were selected from each cadre in each unit using simple random sampling technique.

Data Collection Tool A pre-tested self-administered structured questionnaires was used to collect information on respondents' socio-demographic variables (age, level of education, marital status), rank, duration in service, keeping multiple non regular sexual partners, engagement in casual and transactional sex.

\section{Variables}

Independent variables were age, duration in service, educational qualifications, rank, marital status, religion and ethnic group. The dependent variable, risky sexual behaviour, was measured using a series of 
high-risk sexual behaviour questions based on the past 12 months sexual experience [14]. The high-risk sexual behaviours examined are; transactional sexual intercourse in the past 12 months, having more than one non-regular sexual partner in the past 12 months and sexual intercourse with casual acquitances in the past 12 months. To measure transactional sex, participants were asked how many non-regular partner with whom they had sexual intercourse in exchange for money/favours or gifts during the past 12 months. Respondents that reported at least one non-regular partner were classified as having transactional sex.

For sex with multiple sexual partners during the past 12 months, respondents were asked how many nonregular partners they had sex with during the past 12 months, those that reported more than one nonregular sexual partner were classified as having multiple sexual partners.

Sex with casual acquaintances was measured by asking the the respondents the sexual experience with partner to whom they were not married to, had never lived with, were not their boyfriend or girlfriend and did not pay for sex during the past 12 months. Respondents that reported at least one casual partner were classified as having sex with casual acquitances.

\section{Statistical Analyses}

The data were cleaned prior to analysis using IBM SPSS statistical software version 20.0 [15]. Frequency distributions of variables were generated and represented in tables and charts. Chi-square test was used to examine the association between RSB and socio-demographic characteristics. Factors significantly associated with RSB at bivariate level (at most 10\% level of significance) and those that were found to be important predictors of risky sexual practices from the literature [16] were used in the logistic regression model for the identification of predictors of RSB. The level of significance was $5.0 \%$.

\section{Ethical Considerations}

The study ethical approval was obtained from the Health Research Ethics Committee of the Aminu Kano Teaching Hospital. (NHREC/21/08/2008/AKTH/EC/2242). Permission to conduct this study was given by Comptrollers of immigration and correctional Services in Kano State. Written informed consent was obtained from all respondents selected for participation in this study.

\section{Results}

The mean ages of respondents in the immigration and correctional services were $38.1 \pm 9.4$ and $39.4 \pm$ 7.9 years respectively. Most of the respondents (49.5\%) in the study were in the age group 35-49 years. About a third (30.9\%) of immigration and correctional respondents were junior officer. Majority of respondents from both services $(71.7 \% \%$ immigration and $93.4 \%$ correctional) were Hausa and of the Islamic faith (76.5\% and $94.7 \%)$, respectively (Table 1$)$.

A significantly higher proportion (18.4\%) of correctional officers had sexual intercourse with non-regular partners after clubbing compared to $9.8 \%$ among immigration personnel. However, over a tenth of 
immigration (11.8\%) and $9.2 \%$ of correctional personnel drank alcohol prior to sexual intercourse with non-regular partner (Table 2).

Overall, about one-fifth (15.1\%) of correctional and immigration personnel engaged in risky sexual behaviours in the last 12 months. Specifically, $9.2 \%$ of correctional personnel compared to $20.9 \%$ of immigration officers were involved in risky sexual behaviours (Fig. 1).

Ethnicity, marital status and clubbing were significantly associated with risky sexual behaviour among correctional workers while Use of performance enhancing drug, alcohol misuse and clubbing were significantly associated with risky sexual behaviour among immigration personnel (Table 3).

At the multivariate level, after adjusting for the covariates, service group, marital status and clubbing remained significant predictors of risky sexual behaviour among correctional and immigration personnel. Respondents from the correctional service were $62 \%$ less likely to engage in risky sexual behaviour compared with those from immigration service $(\mathrm{aOR}=0.38,95 \% \mathrm{Cl}=0.17-0.80)$. Correctional and immigration personnel who were single were $38 \%$ more likely to get involved in risky sexual behaviour compared with those that were married. $(\mathrm{aOR}=0.38,95 \% \mathrm{Cl}=0.18-0.81)$. Correctional and immigration personnel who went for clubbing prior to sexual intercourse were abused drugs 3 times as likely to be involved in risky sexual behaviour compared with those who did not go for clubbing $(\mathrm{aOR}=3.90,95 \% \mathrm{Cl}=$ 1.30-11.68) (Table 4).

\section{Discussion}

The study aimed to determine the prevalence and identify the predictors of risky sexual behaviour among immigration and correctional workers in Kano State. Overall, prevalence of risky sexual behaviour was found to be high among study participants. The study showed that one in every five immigration and correctional workers in Kano State engaged in risky sexual behaviour. Looking at each arm of the study participants, there appeared to be higher proportions of immigration personnel engaging in risky sexual behaviour compared with correctional workers. However, the prevalence of risky sexual behaviour from the study was far lower than that reported in southwest Nigeria $[17,18]$. The variation in results could be due to the differences in terms of study participants, data collection procedure and operational definition of sexual risk behavior in these studies and ours.

About one-tenth of both immigration and correctional workers had more than one non-regular sexual partner. This figure is far below $46 \%$ reported among uniformed personnel in Cote D'Ivoire [19]. The contextual nature of the studies environment can explain the difference in the outcomes. The conservative and restrictive nature of northern Nigerian culture (sharia laws are being enforced), especially, in the ancient city of Kano and other parts of the state where this study was conducted could be an important reason for the low prevalence found in our study. Less than one-tenth of the study participants had sexual intercourse with casual acquaintances. This finding contrasts with what was reported in Dominican Republic and Haiti in which $40 \%$ of uniformed personnel stationed across the border zone reported having casual sex [20]. 
Over a tenth of correctional (12.8\%) and immigration (15.2\%) personnel in Kano State were found to have paid or exchanged gifts with sexual partners in the last 12 months. These findings corroborate earlier outcome of a similar study which was conducted among uniformed personnel in Rwanda and Afghanistan [21]. However, our findings were much lower than $43 \%$ that was reported in a nationwide survey among Thai uniformed personnel. The differences in findings could be due to the fact that most new recruits are likely to be single or have non-regular partners, less inclined to abstinence and more likely to engage in transactional sex [22].

The proportion of immigration and correctional personnel who had multiple sexual partners in Kano State was in line with to what was reported in Southeast Nigeria [23]. However, the higher percentage of immigration and correctional personnel who had multiple sexual partners was still lower than what was reported among Ethiopian officers [24].

Service group, marital status and clubbing were identified to be independent predictors of risky sexual behaviour among the correctional personnel in Kano State. These findings were in contrast to a survey which evaluated sexual risk taking and related behaviours among uniformed personnel in four regions of Angola [25] in which alcohol misuse before sex was found as an independent predictor of risky sexual behaviour. Alcohol and drug use were found to be associated with risky sexual behaviour among correctional and immigration personnel however, the two variables were found not to be predictors of risky sexual behaviour among the immigration and correctional personnel in Kano State. The study is not without limitation. Due to self-reporting nature of the study, there may be some level of social desirability bias because some study participants might have under or over reported the degree to which they engaged in high-risk sexual behaviours. Assurance of confidentiality likely minimized this bias.

\section{Conclusions}

Risky sexual behaviour was highly prevalent among the investigated uniform men. However, the prevalence of RSB was higher among immigration officers than the correctional personel. Effective health education on the possible implication of RSB is highly recommended for immigration and correctional personnel.

\section{Abbreviations}

AFENET: African Field Epidemiology Network; NFELTP: Nigeria Field Epidemiology and Laboratory Program; OR: odds ratio; aOR: Adjusted Odds Ratio; RSB: Risky Sexual Behaviour; STI: Sexually Transmitted Infection; HIV: Human Immunodeficiency Virus; IBBSS: Integrated Behavioural and Biomedical Surveillance Survey; IBM: International Business Machine; SPSS: Statistical Package for the Social Sciences; LGA: Local Government Area; AKTH: Aminu Kano Teaching Hospital

\section{Declarations}




\section{Ethics approval and consent to participate}

Ethical approval was obtained from the Ethics and Research Committee of Aminu Kano Teaching Hospital (NHREC/21/08/2008/AKTH/EC/2242). Permission to conduct this study was given by Comptrollers of immigration and correctional Services in Kano State. Informed written consent was obtained from the study participants before the commencement of the study. Participants were informed that participation was entirely voluntary and were given the option of voluntary withdrawal of their participation at any stage of the study without sanction or penalty. Information obtained from the respondents was treated as confidential.

\section{Consent for publication}

Not applicable.

\section{Availability of data and materials}

Data can be made available by the corresponding author based on reasonable request.

\section{Competing interests}

The authors declare that they have no competing interests.

\section{Funding}

No funding was received for the research work

\section{Authors' contributions}

NA was the Principal Investigator, conceptualized and designed the study, collected, analysed and interpreted the data, and wrote draft manuscript. ZI and AMJ were academic supervisors and contributed to study design, data interpretation, drafting and formatting of manuscript. AAS and ABU contributed in data interpretation, drafting, and revision of the manuscript for intellectual content. All authors read and approved the final revised manuscript.

\section{Acknowledgements}

The support of the Africa Field Epidemiology Network (AFENET) through the Nigeria Field Epidemiology and Laboratory Training Program (NFELTP) for providing opportunity to attend workshop on manuscript writing. Also, the co-operation enjoyed from the heads of Nigeria immigration and correctional services in Kano State. Finally, the esteemed study participants who consented to participate in the study despite their tight schedule are appreciated.

\section{Author details}

1. Nigeria Field Epidemiology and Laboratory Program 
2. Africa Field Epidemiology Network, Asokoro Abuja, Nigeria

3. Department of Epidemiology and Medical Statistics, University of Ibadan, Nigeria

4. Department of Community Medicine, Bayero University, Kano, Nigeria

\section{References}

1. Mirzaei M, Ahmadi K, Saadat S-H, Ramezani MA. Instruments of High Risk Sexual Behaviour Assessment: A Systematic Review. Mater Sociomed. 2016 Feb;28(1):46-50.

2. Imaledo J, Peter-Kio O, Asuquo E. Pattern of risky sexual behavior and associated factors among undergraduate students of the University of Port Harcourt, Rivers State, Nigeria. Pan Afr Med J. 2012;8688:1-9.

3. Perez A, Bensenor I. Tobacco and alcohol use, sexual behavior and common mental disorders among military students at the Police Academy, São Paulo, Brazil. Sao Paulo Med J. 2015;133(3):235-44.

4. Hussein NAA, Akande TM. Sexual Behaviour and Condom use among Nigerian Soldiers in llorin, Kwara State, Nigeria. Africa J Clin Exp Microbiol. 2009;10(2):128-35.

5. Villaran MV, Bayer A, Konda KA, Mendoza C, Quijandria H, Ampuero JS, et al. Condom Use by Partner Type Among Military and Police Personnel in Peru. Am J Mens Health. 2012;6(4):266-72.

6. Igboanusi CJ, Dahiru T, Joshua IA. HIV / AIDS Knowledge and Attitude among Military Recruits at Depot Nigeria Army, Zaria, Nigeria. Am J Public Heal Res. 2015;3(1):8-14.

7. Mankayi N, Naidoo AV. Masculinity and Sexual Practices in the Military: a South African Study. African J AIDS Res. 2011;10(1):43-50.

8. Feldbaum H, Lee K, Patel P. The national security implications of HIV/AIDS. PLoS Med. 2006 Jun;3(6):0774-8.

9. Feldbaum H, Lee K, Michaud J. Global Health and Foreign Policy. Epidemiol Rev. 2010;32:82-92.

10. Biague A, Månsson F, Silva Z, Dias F, Nantote Q, Andersson S, et al. High sexual risk taking and diverging trends of HIV-1 and HIV-2 in the military of Guinea Bissau. J Infect Dev Ctries. 2010;4(5):301-8.

11. Selgelid MJ, Enemark C. Infectious diseases, security and ethics: the case of HIV/AIDS. Bioethics [Internet]. 2008 Nov [cited 2016 Jun 16];22(9):457-65. Available from: http://www.ncbi.nlm.nih.gov/pubmed/18959728.

12. Aldous WK, Robertson JL, Robinson BJ, Hatcher CL, Hospenthal DR, Conger NG, et al. Rates of gonorrhea and Chlamydia in U.S. military personnel deployed to Iraq and Afghanistan (2004-2009). Mil Med. 2011;176(6):705-10.

13. FMOH. National HIV,. AIDS \& STIs Control Programme Federal Ministry of Health, Nigeria Integrated Biological and Behavioural Surveillance Survey (IBBSS). 2014.

14. Norris AE, Phillips RE, Statton MA, Pearson TA. Condom Use by Male, Enlisted, Deployed Navy Personnel with Multiple Partners. Mil Med. 2005;170(10):898-904. 
15. Corporation IBM. IBM SPSS Statistics 20 Brief Guide. 2011. p. 1-159.

16. Katz M. multivariate analysis: A Pratical Guide for Clinical and Public Health Researchers. Third Edit. Cambridge; 2011. 138-139 p.

17. Essien EJ, Monjok E, Chen H, Abughosh S, Ekong E, Peters RJ, et al. Correlates of HIV knowledge and sexual risk behaviors among female military personnel. AIDS Behav. 2010;14(6):1401-14.

18. Nwokoji UA, Ajuwon AJ. Knowledge of AIDS and HIV risk-related sexual behavior among Nigerian naval personnel. BMC Public Health. 2004;4:24.

19. Talnan E, Adjoua AD, Kouakou KV. HIV prevention in the armed forces: determinants of condom use with non-spousal partners among the military in Cote d'Ivoire. XVII International AIDS Conference. 38 August, 2008 Mexico City, Mexico. 2008.

20. Anastario MP, Tavarez MI, Chun H. Sexual risk behavior among military personnel stationed at border-crossing zones in the Dominican Republic. Pan Am J public Heal. 2011;28(5):361-7.

21. Oumar BA, Christopher O, Jean N, Curtis C, Aranka ABR, et al. HIV / AIDS in African militaries: an ecological analysis. Med Confl Surviv. 2008;24(2):88-100.

22. Adelekan AL, Musa G, Aliyu H, Obinatu R, Shaibu W, Adah P, et al. Achievements and implications of HIV prevention programme among uniform service personnel: a systematic evaluation of HAF II project in Kogi state, Nigeria. Int J Community Med Public Heal. 2017;4(2):613-9.

23. Okeke CE. The effect of age on knowledge of HIV / AIDS and risk related behaviours among army personnel. Afr Health Sci. 2012;12(3):291-6.

24. Argaw R, Seyoum B, Egata G. Influencing preventive behavior with regard to HIV/AIDS among the Police Force of Harari Region, Eastern Ethiopia, 2011. Ethiop J Heal Dev. 2012;26(1):3-8.

25. Bing EG, Ortiz DJ, Ovalle-bahamón RE, Cheng KG, Fannie H. HIV / AIDS Behavioral Surveillance among Angolan Military Men. AIDS Behav. 2010;12(4):578.

\section{Tables}

Table 1 Socio-demographic characteristics of immigration and correctional personnel in Kano State, Nigeria (N=305) 


\begin{tabular}{|c|c|c|c|}
\hline Characteristics & Correctional & Immigration & Total \\
\hline & $152(100.0)$ & $153(100.0)$ & $305(100.0)$ \\
\hline \multicolumn{4}{|l|}{ Age (years) } \\
\hline $18-24$ & $2(1.3)$ & $4(2.6)$ & $6(2.0)$ \\
\hline $25-34$ & $42(27.6)$ & $60(39.2)$ & $102(33.4)$ \\
\hline $35-49$ & 86 (56.6) & $65(42.5)$ & $151(49.5)$ \\
\hline $50-60$ & $22(14.5)$ & $24(15.7)$ & $46(15.1)$ \\
\hline$M e a n \pm \sigma$ & $39.4 \pm 7.9$ & $38.1 \pm 9.4$ & $38.7 \pm 8.7$ \\
\hline \multicolumn{4}{|l|}{ Level of education } \\
\hline Secondary & $19(12.5)$ & $23(15.0)$ & $42(13.8)$ \\
\hline Tertiary & $133(87.5)$ & $130(85.0)$ & $263(86.2)$ \\
\hline \multicolumn{4}{|l|}{ Religion } \\
\hline Christianity & $8(5.3)$ & 36 (23.5) & $44(14.4)$ \\
\hline Islam & $144(94.7)$ & $117(76.5)$ & $261(85.6)$ \\
\hline \multicolumn{4}{|l|}{ Ethnicity } \\
\hline Hausa/Fulani & $142(93.4)$ & $110(71.9)$ & $252(82.6)$ \\
\hline Igbo & $0(0.0)$ & $7(4.6)$ & $7(2.3)$ \\
\hline Yoruba & $2(1.3)$ & $10(6.5)$ & $12(3.9)$ \\
\hline Others* & $8(5.3)$ & $26(17.0)$ & $34(11.1)$ \\
\hline \multicolumn{4}{|l|}{ Marital status } \\
\hline Married & $138(90.8)$ & $117(76.5)$ & 255 (83.6) \\
\hline Single & $14(9.2)$ & 36 (23.5) & $50(16.4)$ \\
\hline \multicolumn{4}{|l|}{ Family Type } \\
\hline Monogamy & $79(52.0)$ & $110(71.9)$ & $189(62.0)$ \\
\hline Polygamy & $73(48.0)$ & $43(28.1)$ & $116(38.0)$ \\
\hline \multicolumn{4}{|l|}{ Rank in service } \\
\hline Junior & $57(37.5)$ & $37(24.2)$ & $94(30.8)$ \\
\hline Senior & $95(62.5)$ & $116(75.8)$ & $211(69.2)$ \\
\hline \multicolumn{4}{|c|}{ Length in service (years) } \\
\hline$<10$ & $68(44.7)$ & 79 (51.6) & $147(48.2)$ \\
\hline$\geq 10$ & $84(55.3)$ & $74(48.4)$ & $158(51.8)$ \\
\hline Median (Range) & $11(2-35)$ & $9(1-35)$ & $10(1-35)$ \\
\hline
\end{tabular}

*Others include; Kanuri, Tarok, Idoma, Babur, Nupe, Tiv and Baju.

Table 2 Risky activities prior to sexual intercourse with non-regular partner in the last 12months among immigration and correctional personnel in Kano State, Nigeria $(\mathrm{N}=305)$ 


\begin{tabular}{|l|l|l|l|}
\hline Variable & Correctional(n=152) & Immigration(n=153) & Total \\
\hline Clubbing & & & \\
\hline Yes & $28(18.4)$ & $15(9.8)$ & $43(14.1)$ \\
\hline No & $124(81.6)$ & $138(90.2)$ & $262(85.9)$ \\
\hline Drug & & & \\
\hline Yes & $14(9.2)$ & $18(11.8)$ & $32(10.5)$ \\
\hline No & $138(90.8)$ & $135(88.2)$ & $273(89.5)$ \\
\hline Alcohol & & & $24(7.9)$ \\
\hline Yes & $12(7.9)$ & $12(7.8)$ & $281(92.1)$ \\
\hline No & $140(92.1)$ & $141(92.2)$ & \\
\hline Smoking & & & $20(6.6)$ \\
\hline Yes & $12(7.9)$ & $8(5.2)$ & $285(93.4)$ \\
\hline No & $140(92.1)$ & $145(94.8)$ & \\
\hline
\end{tabular}

Table 3 Factors associated with risky sexual behaviours among immigration and correctional personnel in Kano State, Nigeria (N=305) 


\begin{tabular}{|c|c|c|c|c|c|c|}
\hline Background & \multicolumn{2}{|c|}{ Correctional } & & \multicolumn{2}{|c|}{ Immigration } & \\
\hline Characteristics & \multicolumn{2}{|c|}{ ASRB } & $x^{2}$ & \multicolumn{2}{|c|}{ ASRB } & $x^{2}$ \\
\hline & Yes & Total & ( $p$ value) & Yes & Total & ( $p$ value) \\
\hline Age & & & 0.001 & & & 1.110 \\
\hline $18-34$ & $4(9.1)$ & 44 & $(0.974)$ & $30(20.7)$ & 145 & $(0.292)$ \\
\hline $35+$ & $10(9.3)$ & 100 & & $16(25.0)$ & 64 & \\
\hline \multicolumn{3}{|c|}{ Level of education } & 0.405 & & & 0.011 \\
\hline Secondary & $1(5.3)$ & 19 & $(0.525)$ & $5(21.7)$ & 23 & $(0.916)$ \\
\hline Tertiary & $13(9.8)$ & 133 & & $27(20.8)$ & 130 & \\
\hline Religion & & & 0.857 & & & 1.340 \\
\hline Christianity & $0(0.0)$ & 8 & $(0.355)$ & $10(21.7)$ & 36 & $(0.247)$ \\
\hline Islam & $14(9.7)$ & 144 & & $22(18.8)$ & 117 & \\
\hline Ethnicity & & & 5.533 & & & 0.777 \\
\hline Hausa/Fulani & $11(7.7)$ & 142 & $(0.019)^{*}$ & $25(22.7)$ & 110 & $(0.378)$ \\
\hline Other tribes & $3(30.0)$ & 10 & & 7 (16.3) & 43 & \\
\hline \multicolumn{2}{|l|}{ Marital status } & & 6.91 & & & 2.645 \\
\hline Married & $10(7.2)$ & 138 & $(0.009)^{*}$ & 21 (17.9) & 117 & $(0.104)$ \\
\hline Single & $4(28.6)$ & 14 & & $11(30.6)$ & 36 & \\
\hline Family Type & & & 0.165 & & & 1.752 \\
\hline Monogamy & $8(10.1)$ & 79 & $(0.685)$ & $26(23.6)$ & 110 & $(0.186)$ \\
\hline Polygamy & $6(8.2)$ & 73 & & $6(14.0)$ & 43 & \\
\hline \multicolumn{2}{|l|}{ Rank in service } & & 0.524 & & & 0.118 \\
\hline Junior & $4(7.0)$ & 57 & $(0.469)$ & 7 (18.9) & 37 & $(0.732)$ \\
\hline Senior & $10(10.5)$ & 95 & & $25(21.6)$ & 116 & \\
\hline \multicolumn{3}{|c|}{ Length in service (years) } & 2.384 & & & 0.043 \\
\hline$<10$ & $9(13.2)$ & 68 & $(0.123)$ & $16(20.3)$ & 79 & $(0.835)$ \\
\hline$\geq 10$ & $5(6.0)$ & 84 & & $16(21.6)$ & 74 & \\
\hline Clubbing & & & 6.134 & & & 10.567 \\
\hline Yes & $6(21.4)$ & 28 & $(0.013) *$ & $8(53.3)$ & 15 & $(0.001)^{*}$ \\
\hline No & $8(6.5)$ & 124 & & $24(17.4)$ & 138 & \\
\hline Drug & & & 0.475 & & & 6.828 \\
\hline Yes & $2(14.3)$ & 14 & $(0.491)$ & $8(44.4)$ & 18 & $(0.009)^{*}$ \\
\hline No & $12(8.7)$ & 138 & & $24(17.8)$ & 135 & \\
\hline Alcohol & & & 0.866 & & & 11.022 \\
\hline Yes & 2 (16.7) & 12 & $(0.352)$ & 7 (58.3) & 12 & $(0.001)^{*}$ \\
\hline No & $12(8.6)$ & 140 & & $25(17.70$ & 141 & \\
\hline Smoking & & & 0.866 & & & 0.085 \\
\hline Yes & $2(16.7)$ & 12 & $(0.352)$ & $2(25.0)$ & 8 & $(0.770)$ \\
\hline No & $12(8.6)$ & 140 & & $30(20.7)$ & 145 & \\
\hline
\end{tabular}

*Statistically significant difference at $p \llbracket 0.05$; ASRB: At least one risky behaviour

Table 4 Logistic regression model of predictors of risky sexual behaviour among immigration and correctional personnel in Kano State, Nigeria 


\begin{tabular}{|c|c|c|c|}
\hline \multirow{2}{*}{$\begin{array}{l}\text { Background } \\
\text { Characteristics }\end{array}$} & \multirow[b]{2}{*}{ OR (95\% C.I) } & \multirow{2}{*}{$\begin{array}{l}\text { Model } 1 \\
\text { aOR (95\% C.I) }\end{array}$} & \multirow{2}{*}{$\frac{\text { Model } 2}{\text { aOR (95\% C.I) }}$} \\
\hline & & & \\
\hline \multicolumn{4}{|l|}{ Service group } \\
\hline Correctional & $0.38(0.19-0.75)^{* *}$ & $0.31(0.14-0.63)^{* *}$ & $0.38(0.17-0.80)^{* * *}$ \\
\hline Immigration & 1.00 & 1.00 & 1.00 \\
\hline \multicolumn{4}{|l|}{ Age } \\
\hline $18-34$ & $1.50(0.79-2.83)$ & & \\
\hline $35+$ & 1.00 & & \\
\hline \multicolumn{4}{|c|}{ Level of education } \\
\hline Secondary & $0.93(0.36-2.35)$ & & \\
\hline Tertiary & 1.00 & & \\
\hline \multicolumn{4}{|l|}{ Religion } \\
\hline Christianity & $1.84(0.83-4.04)$ & & \\
\hline Islam & 1.00 & & \\
\hline \multicolumn{4}{|l|}{ Ethnicity } \\
\hline Hausa/Fulani & $0.72(0.33-1.55)$ & & \\
\hline Other tribes & 1.00 & & \\
\hline \multicolumn{4}{|l|}{ Marital status } \\
\hline Married & $0.32(0.15-0.66)^{* *}$ & & $0.38(0.18-0.81)^{* * *}$ \\
\hline Single & 1.00 & & 1.00 \\
\hline \multicolumn{4}{|l|}{ Family Type } \\
\hline Monogamy & $1.90(0.94-3.84)^{\mathrm{a}}$ & & $1.70(0.80-3.62)$ \\
\hline Polygamy & 1.00 & & 1.00 \\
\hline \multicolumn{4}{|l|}{ Rank in service } \\
\hline Junior & $0.67(0.32-1.38)$ & & \\
\hline Senior & 1.00 & & \\
\hline \multicolumn{4}{|c|}{ Length in service (years) } \\
\hline$<10$ & $1.34(0.71-2.51)$ & & \\
\hline $10+$ & 1.00 & & \\
\hline \multicolumn{4}{|l|}{ Clubbing } \\
\hline Yes & $3.47(1.66-7.25)^{* *}$ & $3.88(1.32-11.39)^{* * *}$ & $3.90(1.30-11.68)^{* * *}$ \\
\hline No & 1.00 & 1.00 & 1.00 \\
\hline \multicolumn{4}{|l|}{ Drug } \\
\hline Yes & $2.99(1.31-6.83)^{* *}$ & $0.89(0.18-4.23)$ & $0.80(0.16-3.83)$ \\
\hline No & 1.00 & 1.00 & 1.00 \\
\hline \multicolumn{4}{|l|}{ Alcohol } \\
\hline Yes & $3.96(1.61-9.69)^{* *}$ & $1.57(0.26-9.33)$ & 1.78(0.29-10.67) \\
\hline No & 1.00 & 1.00 & 1.00 \\
\hline \multicolumn{4}{|l|}{ Smoking } \\
\hline Yes & $1.45(0.46-4.54)$ & & \\
\hline No & 1.00 & & \\
\hline
\end{tabular}

**Statistically significant difference at bivariate level $p \llbracket 0.05 * * *$ Statistically significant difference at multivariate level $p \llbracket 0.05 \mathrm{OR}$ : Odds ratio, aOR: adjusted odds ratio

\section{Figures}




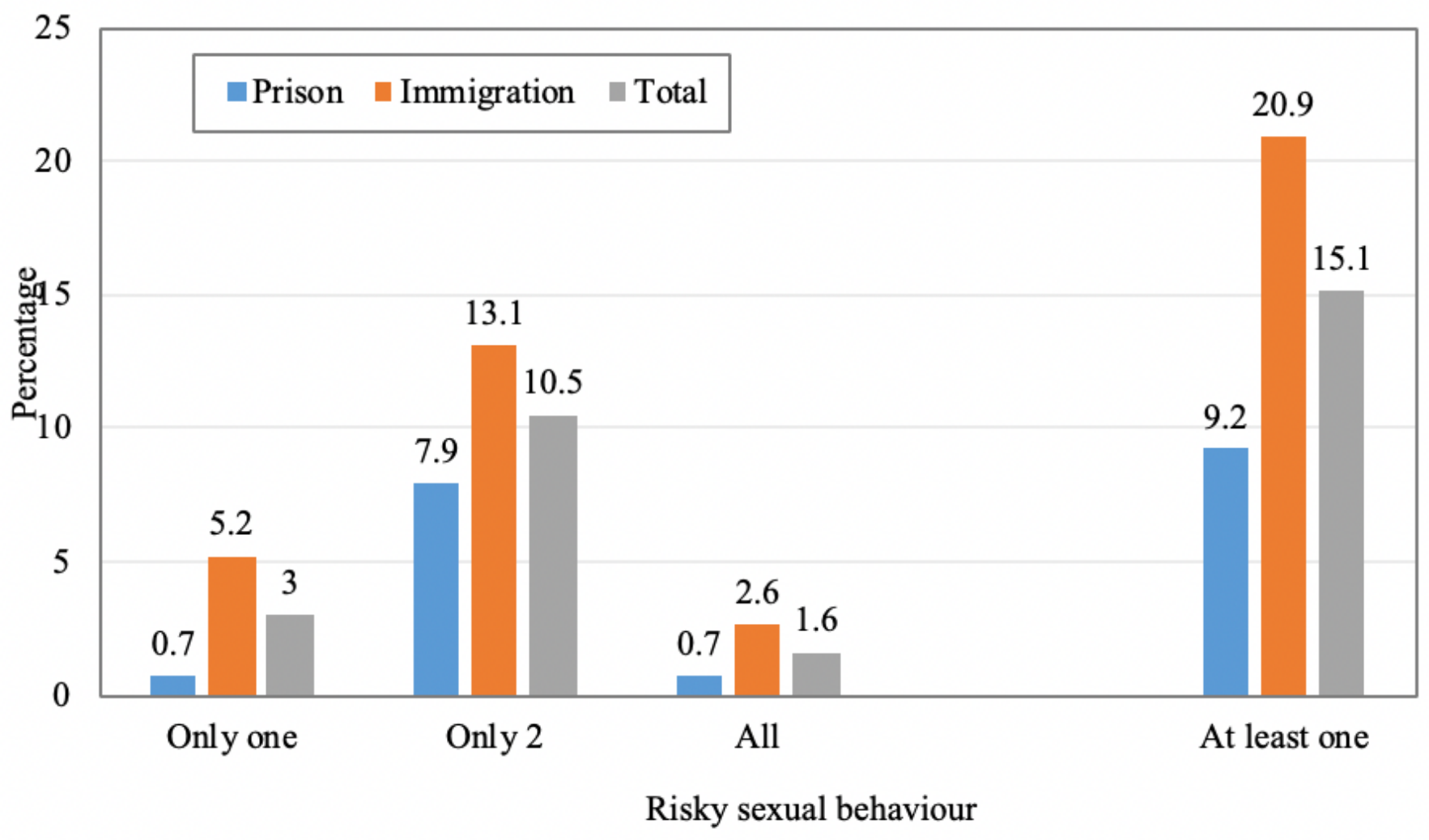

\section{Figure 1}

Prevalence of risky sexual behaviour among immigration and correctional personnel in Kano State, Nigeria 